\title{
Correction to: The role of spinal reciprocal inhibition and intracortical inhibition in functional recovery from stroke
}

\author{
Toshiyuki Fujiwara ${ }^{1,2}$
}

Published online: 28 July 2020

c) Springer-Verlag GmbH Germany, part of Springer Nature 2020

\section{Correction to: Experimental Brain Research}

https://doi.org/10.1007/s00221-020-05849-0

In the original publication of the article, it was published under the title 'Mini-review article: the role of spinal reciprocal inhibition and intracortical inhibition in functional recovery from stroke'. The article type was included by mistake, the correct title is 'The role of spinal reciprocal inhibition and intracortical inhibition in functional recovery from stroke'.

Publisher's Note Springer Nature remains neutral with regard to jurisdictional claims in published maps and institutional affiliations.

The original article can be found online at https://doi.org/10.1007/ s00221-020-05849-0.

Toshiyuki Fujiwara

t-fujiwara@juntendo.ac.jp

1 Department of Rehabilitation Medicine, Juntendo University Graduate School of Medicine, Tokyo, Japan

2 Department of Physical Therapy, Faculty of Health Science, Juntendo University, 2-1-1 Hongo, Bunkyo, Tokyo 113-8421, Japan 